Illinois State University

ISU ReD: Research and eData

$12-2021$

\title{
Using the Cataloguing Code of Ethics Principles for a Retrospective Project Analysis
}

Angela Yon

Illinois State University, ayon@ilstu.edu

Eric Willey

Illinois State University, emwille@ilstu.edu

Follow this and additional works at: https://ir.library.illinoisstate.edu/fpml

Part of the Cataloging and Metadata Commons

\section{Recommended Citation}

Yon, Angela and Willey, Eric, "Using the Cataloguing Code of Ethics Principles for a Retrospective Project Analysis" (2021). Faculty and Staff Publications - Milner Library. 145.

https://ir.library.illinoisstate.edu/fpml/145

This Article is brought to you for free and open access by the Milner Library at ISU ReD: Research and eData. It has been accepted for inclusion in Faculty and Staff Publications - Milner Library by an authorized administrator of ISU ReD: Research and eData. For more information, please contact ISUReD@ilstu.edu. 


\title{
Using the Cataloguing Code of Ethics Principles for a Retrospective Project Analysis
}

\author{
by Angela Yon \& Eric Willey
}

\begin{abstract}
This study uses the recently released Cataloguing Code of Ethics to evaluate a project which explored how to ethically, efficiently, and accurately add demographic terms for African American authors to catalog records. By reviewing the project through the lens of these principles the authors were able to examine how their practice was ethical in some ways but could have been improved in others. This helped them identify areas of potential improvement in their current and future research and practice and explore ethical difficulties in cataloging resources with records that are used globally, especially in a linked data environment.
\end{abstract}

https://doi.org/10.1080/01639374.2021.2012310

\section{Introduction}

Catalogers and metadata creators have researched and discussed the ethical and social justice implications of their work for decades, at least since the work of Dorothy Porter $^{1}$, Frances Yocom ${ }^{2}$, and Annette Phinazee ${ }^{3}$. In January 2021 the Cataloguing Code of Ethics was finalized as a series of "ethical statements based on principles and values identified by the Cataloging Ethics Steering Committee and the Working Groups, with guidance and examples of best practice, that can be shared across the Cataloging community." ${ }^{4}$ In order to provide further guidance and practical examples for community members the creators encouraged the submission of case studies which illustrated the principles of the Cataloguing Code of Ethics. ${ }^{5}$ These case studies are intended to provide concise examples of how the code can guide catalogers facing ethical issues in their work. While these principles may be mostly used to guide present and future practice, insights into past practices which might be improved or areas for 
retrospective work can also be gained by reviewing past projects against the code of ethics.

Inspired by the call for case studies but not fitting the criteria that they be concise, the current study provides a retrospective examination of an Illinois State University (ISU) Research Grant (URG) funded project to add Library of Congress Demographic Group Terms (LCDGT) to Name Authority Title Records and bibliographic records. The project is reviewed against the ten principles of the Cataloguing Code of Ethics (which was not in existence when the project work was being done) to provide an example of how the project may meet or not meet these principles. It is the authors' belief that by evaluating past work against the principles in the code of ethics, catalogers can identify potential areas for improvement in their own practice.

By reviewing a previous project with the Cataloguing Code of Ethics principles in mind the authors were able to see ways in which their practice met the criteria outlined in the "Statements of Ethical Principles," and ways in which their practice did not meet those same principles. This eventually led them to view the statements as less of a checklist and more as a series of prompts which could be used to guide current and future practice in considering the impact of their cataloging and metadata work both locally and more widely. Instead of being a list of items which could be addressed once and then moved on from, the criteria became a method to evaluate a project and determine what was being done, what further could be achieved or improved, and what was out of their reach but should be kept in mind.

This previous project was described in "Applying Library of Congress Demographic Group Characteristics for Creators" in Cataloging \& Classification 
Quarterly. ${ }^{6}$ Briefly, the project tested the idea that many of the individuals on the Wikipedia "List of African American Writers" could be described as African American using the Library of Congress Demographic Group Terms (LCDGT). The project also explored how to add demographic terms for African American authors ethically, accurately, and efficiently to bibliographic records and Name Title Authority Records. Working from names on the Wikipedia "List of African American Writers" with works in local holdings a Department of History graduate student searched for evidence of self-identification as African American for the creators. ${ }^{7}$ Evidence of self-identification as African American was found for $84 \%$ of those creators, and as a subject expert the graduate student felt the other creators would also likely be considered African American. The authors added the demographic terms "African Americans" and "Americans" to 3,053 bibliographic records and some work level Name Title Authority Records for works with holdings in the local catalog. Based on the high level of agreement between Wikipedia editors and evidence of self-identification as African American (which is the highest level of evidence for using the LCDGT to describe a creator) the authors concluded that there was general agreement for who the Wikipedia editor community and LCDGT would describe as African American. While various ethical concerns were raised throughout the project as they occurred to the authors, the release of the Cataloguing Code of Ethics allowed for the review of the project with a publicly available framework.

\section{Literature review}

There is an extensive body of literature on ethics and social justice in cataloging and metadata creation, but as the Cataloguing Code of Ethics is new there is no scholarly literature on using it specifically at the time of writing. This literature review therefore 
provides a general overview on the definition of cataloging ethics and values, current ethical issues in the applications of cataloging standards and description, and areas touched on by the previous project describing creators in bibliographic records with the Library of Congress Demographic Group Terms (LCDGT).

The Cataloging Ethics Steering Committee defines cataloging ethics as "Principles and values that provide an intentional decision-making framework for those who work in cataloging or metadata positions." ${ }^{8}$ According to Jennifer M. Martin, the crux of cataloging ethics addresses "the question of what the appropriate role of the cataloger is with regard to users seeking information, to creators of that information,

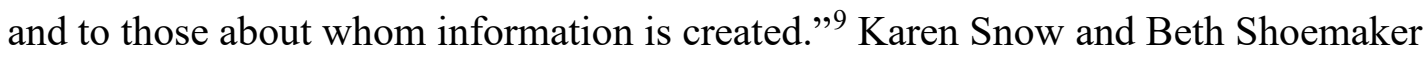
revealed in their study that based on responses to their questionnaire there is not a consensus among the cataloging community on how to define cataloging ethics. ${ }^{10}$ They also found an absence of literature defining cataloging ethics as a concept. ${ }^{11}$ Their study shows that practicing catalogers hold different views on the meaning of ethical cataloging and not all members of the community share the view that ethical issues in cataloging exist. However, they determined five major common values based on varied cataloging ethics definitions:

- Accessibility of resources and metadata

- Awareness of bias at personal, institutional, and standards levels

- Inclusive metadata description

- Accurate representation of resources

- Mindfulness in following standards but also questioning their usefulness

Snow and Shoemaker concluded that these shared values can be translated into working ethical principles to provide a framework for catalogers to act collectively to address ethical challenges. ${ }^{12}$ 
Current issues on cataloging ethics not surprisingly revolve around these major values. Martin discusses these areas, some of which are long-standing debates as cataloging ethics is a concept that goes back as far as the Middle Ages. Significant topics include speed versus detail, descriptive cataloging codes and user needs, equal access to shared standards, neutrality, standards of subject access, authorized access points for names, and privacy. ${ }^{13}$ Many questions do not have a clear answer. For example, both supporters of cataloging for speed and cataloging for detail argue for the needs of the user. Time invested to produce detailed records provide the user with precise and accurate searches. However, speed allows resources to be more quickly available for the users as opposed to having uncataloged items with no access. The ethical question of this matter continues to remain unanswered. ${ }^{14}$

A persistent criticism in discussions of ethical cataloging is that descriptive cataloging codes do not address the actual needs of the users. Martin notes that most studies focus on existing systems, not on the users' behavior and how they search for information. Cataloging standards have not been developed based on user studies and thus catalogers do not know if the codes they follow best serve the user's needs. ${ }^{15}$ Another ethical issue less frequently raised but still of substantial weight is equal access. Tools such as the RDA Toolkit, WebDewey, and ClassWeb are accessible only with subscription fees that potentially create a barrier for catalogers in institutions faced with contracting budgets. ${ }^{16}$

The role of neutrality in description and subject access has also been an ongoing debate in cataloging ethics. Martin summarizes the different thoughts on neutrality as: 1) one can place personal biases aside and represent all sides equally, 2) ridding biases in systems is not neutral but is ethically necessary and social justice is the priority, and 3) neutrality is not possible and is in fact harmful because it strengthens existing 
inequalities. ${ }^{17}$ As an example of these viewpoints Martin discusses how they might treat misleading materials that do not accurately represent their contents. Those in favor of neutrality prefer recording what is only visible on the item, thus (they argue) eliminating personal bias from the cataloger. Believers that neutrality is not possible argue that catalogers should use their judgment and indicate the misleading nature of materials in the catalog records. However, Martin notes, various groups consider what is objectionable differently and it is unclear who decides which viewpoints are appropriate to add or not add. ${ }^{18}$

Amelia Gibson et al. speak on the historical concept of social and political neutrality in libraries. Gibson and her co-authors argue that by electing not to engage with and address the needs of people of color and underrepresented populations as they challenge systemic racism and participate in the political process, libraries are failing to serve the needs of the community. This sort of behavior is not neutrality, and in fact conflicts with one of the libraries' core values and ethics of social responsibility. ${ }^{19}$ Following Gibson et al.'s case against neutrality in library and information science practice, research and pedagogy, social justice as a core value in libraries also encompasses cataloging values for inclusive metadata and awareness of biases at personal, institutional, and standards levels. From this article it can be inferred that taking the stance of neutrality in resource description defeats social justice initiatives within library practices and would equally fail to serve the needs of underrepresented populations and communities.

Rhonda Y. Kauffman and Martina S. Anderson examine how technical services departments can incorporate social justice and bring equitable access to resources for underrepresented groups. ${ }^{20}$ In their discussion, neutrality is not an option in providing equal access to resources. They recommend providing additional access through 
inclusive metadata with terms and vocabularies created by subculture and non-majority communities to ameliorate biases. ${ }^{21}$ To catalog under a diversity, inclusion, and social justice lens, the cataloger should assess if subject headings for groups being described mirror terms used by those groups. They then recommend the addition of other non-LC vocabularies in catalog records to offer a wider, more inclusive range of descriptive terms. Additionally, Kauffman and Anderson recommend actively gathering evidence to propose new terms or changes to Library of Congress Subject Headings (LCSH). ${ }^{22}$

Founded by Violet Fox in 2018, the Cataloging Lab is a crowdsourcing website for the drafting of proposals to revise and create new LCSHs for greater inclusivity. The open platform fosters communication and assistance between catalogers familiar with the research requirements to justify subject headings and others who have expertise in the subject matter being proposed. It allows a wider community to contribute and improve the LCSH vocabulary that is used in many library catalogs. ${ }^{23}$

Discussions in the literature that reveal biases and ethical issues in standards and systems also suggest neutrality in cataloging is not possible. This is especially evident in the description of materials created by individuals from diverse racial and cultural groups. Characteristics of creators and contributors and of the intended audience for resources have always been included in LCSH through the use of subdivisions, such as American fiction -- Indian authors or Families -- Juvenile literature. However, this syntax was not always clear to users and produced ambiguous search results as the headings were used to describe the intended audiences of resources, creators, and the resources themselves. The Library of Congress Genre/Form Terms for Library and Archival Materials (LCGFT) vocabulary began its development in 2007 and offered an alternative to the subdivisions for access to resources by genre separately from the audience and creator/contributor characteristics. ${ }^{24}$ To further address this issue the 
Library of Congress began a pilot in 2016 to develop and test a new vocabulary of demographic group terms and prompt discussion in the library community.

In 2017 the first Library of Congress Demographic Group Terms (LCDGT) and the corresponding manual was released. These demographic group terms describe characteristics of the intended audience and of the creators and contributors of resources. Library of Congress stopped reviewing proposals for new terms in 2018 to allow time for an in-depth evaluation of the principles by the Policy, Training, and Cooperative Programs Division. As of 2020, the LCDGT was comprised of 1,177 approved terms in ten categories: Age group; Educational level group; Ethnic/cultural group; Gender group; Language group; Medical, psychological, and disability group; Nationality/regional group; Occupational/field of activity group; Religious group; Sexual orientation group; and Social group. Terms from multiple categories can be used to describe one individual. ${ }^{25}$ These terms can be added to bibliographic records or work level Name Title Authority Records in the Audience Characteristics (MARC 385) or Creator/Contributor Characteristics (MARC 386) fields. Some catalogs display information from the Audience Characteristics (MARC 385) or Creator/Contributor Characteristics (MARC 386) fields as facets in search results. While no known systems currently use information from those fields in work level Name Title Authority Records, future systems which employ linked data more extensively may do so.

Researchers have found value in adding terms which identify ethnicity for creators and audiences for children books. Krista Maywalt Aronson, Brenna D. Callahan, and Anne Sibley O'Brien discuss the need for multicultural titles for children's picture books, and specifically the ability to search for books about marginalized groups and by authors from those same groups. ${ }^{26}$ Creators from diverse racial and cultural groups are increasingly producing narratives of their own experiences 
for children and the availability of these resources is growing. The authors argue that for books to be truly representative of America's children, this population needs to see themselves reflected as "an integral and valued part of the mosaic." 27 They also question what the library catalog and collection convey to users and how to foster this diverse representation with future acquisitions. ${ }^{28}$

Making diverse materials easily accessible and searchable also requires a standard approach with metadata description. Rachel Ivy Clarke and Sayward Schoonmaker examine missing metadata elements that are required to represent diverse library reading materials. ${ }^{29}$ They found that the need is not simply to describe the resource, but also to reflect the growing plurality of creators narrating experiences from underrepresented populations. Specifically, people from traditionally marginalized communities in the USA, including women and people of non-traditional genders, people of color, indigenous peoples, people identifying as LGBTQIA+, and people with disabilities need access to books and other library resources about or created by people like themselves to see their identities, stories and experiences reflected in contemporary media, and feel empowered to create new works. ${ }^{30}$

However, Clarke and Schoonmaker also found that regardless of the intention that the catalog reflect diversity in collections there are considerable othering and bias issues attached. Access points often contribute to the erasure of identities by categorical metadata, a contradiction to the ALA core value "to provide access to library resources for diverse communities and from diverse populations." ${ }^{31}$ The traditional notion of permanent metadata can also be a hindrance in creating diverse metadata describing a creator. Linked data offers one alternative with the possibility of more flexible 
metadata, and accurate and appropriate self-description (e.g. through Open Researcher and Contributor IDs, or ORCIDs, where users fill in metadata about themselves). This opens the door for the authority of description to reside with the creator. ${ }^{32}$ However, there is the caveat that a creator may desire privacy and prefer not to self-identify, and therefore not contribute to the accessibility of diverse materials through this method.

While there may be a need and desire to describe resources created by and for diverse individuals and provide inclusive subject access, many ethical issues and problems arise as to how to address biases, whether catalogers should label creators, the logistics of how to do so, and generally how to provide metadata ethically in the $21^{\text {st }}$ century. Hope A. Olson and Rose Schlegl note that careful application requires a standard be fully and accurately utilized, but equitable application requires adaptation to local context and responsibility taken by local professionals, whether "local" is at the institutional, national or cultural level. ${ }^{33}$ Brian M. Watson elaborates that many metadata schemas and vocabularies exist to address the inclusion of diverse description by gender, occupation, ethnicity, geographic region, audience, and age, but most are not fully integrated in the $21^{\text {st }}$ century catalog. ${ }^{34}$ Clarke and Schoonmaker assert that catalogers must also acknowledge that none of these representations are neutral, and there is always either an implicit or explicit bias that is brought into descriptions, collections, and catalogs through their metadata. ${ }^{35}$

A frequently examined topic in ethical cataloging is the Library of Congress Subject Headings. Perhaps the most well-known criticism of LCSH is Sanford Berman's 1971 monograph Prejudices and Antipathies: A Tract on the LC Subject Heads Concerning People. In this text, Berman listed objectionable terms and suggested alternative subject headings to existing LCSH. Writing thirty years later, Steven A. Knowlton examines Berman's recommendations in light of then current practice to see 
if they had been implemented. ${ }^{36}$ Of the 225 changes in LCSH recommended by Berman, 88 (39\%) had been changed as recommended and an additional $54(24 \%)$ had been partially changed. ${ }^{37}$ Knowlton concludes that while bias is an ongoing source of concern in LCSH, and Berman's recommended changes to headings related to the Christian religion and U.S. Geography were not implemented, generally bias "has been addressed in a serious manner by the compilers of LCSH." ${ }^{38}$

Sara A. Howard and Knowlton point out the shortcomings of Library of Congress subject headings and classification when working with interdisciplinary subjects. ${ }^{39}$ Working specifically with research materials in African American and LGBTQIA studies, Howard and Knowlton determined that Library of Congress Subject Headings “often employ language and precoordinated strings that serve to 'other' historically marginalized people." 40 The interdisciplinary nature of African American and LGBTQIA research also results in fragmented shelf locations when Library of Congress call number classification is applied. This makes shelf browsing difficult or impossible, and requires librarians and researchers to know how to retrieve material in multiple disciplines when searching. ${ }^{41}$ To address these deficiencies they compiled a list of prominent classification numbers where works on African American Studies and LGBTQIA Studies might be found, and recommended that librarians have discussions with patrons about conducting interdisciplinary research and subject headings. ${ }^{42}$

Innate biases are also widely acknowledged in the Library of Congress Classification (LCC) and Dewey Decimal Classification (DDC) systems. Criticisms have focused on the biases and limits of representation in the systems to serve diverse populations in areas of gender, sexuality, race, age, ability, ethnicity, language and religion. ${ }^{43}$ Patrick Keilty specifically addresses how subject classification and ontologies can find it difficult to account for queer phenomena. ${ }^{44}$ Keilty concludes that 
this is largely a product of trying to place queer topics in a system which relies on "consolidated identity categories." ${ }^{45}$ Keilty recommends that "future scholarship must exam the relationship between Western hierarchical knowledge structures and social power dynamics, as well as the formative power of knowledge structures on our understanding and social relations." ${ }^{46}$ Finally, Keilty also notes that "the consolidation of queer subjects into discernible categories necessarily normalizes the phenomenon, no longer rendering it queer." 47

Molly Higgins examines the DDC as it relates to the history of the term "Asian American." 48 Higgins finds that "with the advent of Tables, racial classes decline while ethnic classes expand, suggesting a preference for ethnic, rather than racial terms." 49 Higgins further finds that relying on literary warrant, the standard that the amount of published literature justifies the presence of a classification, ${ }^{50}$ reinforces colonial terminology in general and specifically for Asian and Asian American communities who were not consulted during the creation of categories which attempt to describe them. ${ }^{51}$ To ameliorate this Higgins suggests greater community control over ontologies, possibly through "hyperlinking, social tagging, and user-sourced knowledge." 52

Outside of subject headings and classifications, there is also the opportunity for inclusivity and diversity in authority work for identification of creators and authors, although this generates additional ethical and moral questions. In 2017 Brian Dobreski and Barbara H. Kwaśnik examined how libraries depict people as information in a variety of ways, including through authority work. ${ }^{53}$ Dobreski and Kwaśnik note that more recent cataloging standards such as RDA allow for information in authority records from any source, and that this may conflict with a creator's desire for privacy and confidentiality. ${ }^{54}$ Dobreski and Kwaśnik also note that while data may be created with a specific group of users in mind, there is no singular public and it may not be 
useful to other users. ${ }^{55}$ As libraries move towards linked data, they must be aware that partners such as Wikidata will bring their own policies, practices, and ethics. Writing in 2013, Jinfang $\mathrm{Niu}^{56}$ hypothesizes that "globally unique IDs will be used in place of authorized headings to disambiguate agents and collocate their works." ${ }^{57}$ Niu notes that these identity systems will be linked to library authorities, resulting in expanded coverage and reduced cost for authority control; however, these changes will also require consideration of how they might impact creators, especially members of marginalized communities. ${ }^{58}$

Kelly J. Thompson examined metadata in authority records for creators who self-identify as trans after the adoption of Functional Requirements for Authority Data (FRAD) and Resource Description and Access (RDA). ${ }^{59}$ Thompson's research focuses on determining if the resulting expanded list of attributes included in Library of Congress Name Authority Records (NAR) is "an inclusive practice, and if it serves the best interests of either authors or library users." 60 Thompson demonstrates that including gender information in NARs for trans creators is a form of outing them, and can cause harm to a creator. ${ }^{61}$ As a possible solution, Thompson offers linked data systems connected to platforms where authors can self-describe to the extent they desire (using ORCIDs for example), recommends that catalogers not include the MARC 375 Gender field in NARs unless they have clear permission from the creator, and only include information relevant to the item being cataloged in other fields. ${ }^{62}$

One way to address these issues may be the support of information systems that do not rely on a single unique text string as an identifier and incorporate identity management principles through linked data. In addressing issues of hidden bias, Melanie Feinberg argues that "an inclusive approach to information system design might involve the definition and justification of a particular stance toward the 
information, as appropriate for the use context of a particular system." ${ }^{63}$ Feinberg advocates that knowledge systems provide rationalization and defend their choices in creating information systems, and pushes back against the concept of a universal and "ideal definition." 64 This acknowledgement of the decisions made in the design process becomes a key part of the design, adding context for users in Feinberg's approach. ${ }^{65}$

Ruth Kitchin Tillman explores barriers to ethical name modeling in linked data practices. ${ }^{66}$ Among these barriers are deciding who should be considered the authority on naming, challenges to encoding, multiplicity in representation (which presents both opportunities and challenges), and challenges with existing infrastructure. ${ }^{67} \mathrm{Of}$ particular relevance to discussions of linked data, Tillman notes that Despite the potential it offers for incorporating unheard voices, a multiplicity of representation or viewpoints does not inherently lead to ethical behavior or the prioritization of voices which have been excluded by white supremacist, patriarchal practices. If we wish to use linked data for name authorities as a tool to promote ethics and justice, we cannot expect the technology to be any less vulnerable to exploitation than others. $^{68}$

This can also lead to inconsistent and conflicting metadata by users of different platforms, especially if systems try to integrate metadata from users in cultures who view ethical cataloging and metadata differently.

The literature review demonstrates discussion on issues in the Cataloguing Code of Ethics, and while the individual principles are not footnoted the code does include a general bibliography. ${ }^{69}$ Attempting to codify the specific conclusions from the entire body of research on ethics in cataloging and metadata would likely lead to a voluminous manual which might still not answer all of a practitioner's questions. Instead the 
Cataloguing Code of Ethics distils it into ten general statements which catalogers interpret and apply according to their professional judgment, as was done in the analysis which follows.

\section{Analysis}

The italicized items are from "Part 2: Statements of Ethical Principles" in the Cataloguing Code of Ethics. ${ }^{70}$ They are presented in the order they are found in the code, which assigns no relative importance based on their order. As previously mentioned, the authors have evaluated a project to evaluate agreement between LCDGT guidelines and Wikipedia editors on who would be considered African American, and how to ethically add the demographic group term African Americans to bibliographic and Name Title Authority Records. This project was completed before the Cataloguing Code of Ethics was available, but the present paper is provided to illustrate how past practice was successful or could be improved. The ethical principles outlined are necessarily general, and the authors often felt they satisfied a principle in some ways while not satisfying it in others. In the absence of a method to objectively measure the "ethicalness" of specific actions, whether the principle was ultimately satisfied or not is left to the judgment of the reader.

(1) We catalogue resources in our collections with the end-user in mind to facilitate access and promote discovery. The authors consulted reference librarians and subject liaisons at Milner Library to verify if a facet in catalog search results showing demographic information about creators would be useful, and if so which demographic groups might be most useful for librarians and patrons. Two groups were suggested: African Americans and child composers. Librarians reported that they received requests for materials specifically by members of both groups. None of the authors were music 
catalogers or had a background in African American Studies. It was decided that the project would focus on African American creators as the university offered a minor in African American Studies, and a subject expert in that area would likely be easier to locate than a music cataloger.

Although the authors did not have the Code of Ethics to consult at the time, they did target their work specifically to a group which could benefit from improved discovery as identified by reference librarians and subject liaisons. However, the software used by their OPAC and time constraints limited the impact of the project. The authors have not been able to do follow-up or user studies to evaluate the exact level of impact, as the library's consortium migrated from Voyager to Alma and Primo VE in July of 2020. The current system includes Community, Network, and Institutional Zone records. Voyager records from various consortial institutions were used as Network Zone records, and Milner Library's bibliographic records were not always made the new Network Zone record. The Creator/Contributor Characteristics (MARC 386) fields were also added to records in OCLC Worldcat and should be added to our consortial catalog records when the functionality to update those records from the OCLC records is implemented. However, currently only some of the added Creator/Contributor Characteristics (MARC 386) fields are available for searching. If the library does decide to include the Creator/Contributor facet in search results, extensive consideration and planning will be needed to add the field in all relevant records or the results will be a limited and misleading representation of resources. Users may also be confused if there is a facet for African American authors, but not authors from other demographic groups.

(2) We commit to describing resources without discrimination whilst respecting the privacy and preferences of their associated agents. 
The project was careful to follow Library of Congress guidelines when creating metadata describing creators. LCDGT guidelines state that self-identification as a member of a demographic group is the highest level of proof, followed by reasonable evidence, and then scholarly consensus. The project's subject expert was given these criteria and focused his initial searches on interviews with creators who might selfidentify as African American. Commercially published and publicly available resources were used, although some resources were in paid subscription databases that create a barrier to accessibility. As much of this information was found in interviews which the creator knew would be published, this helped to meet the requirement to respect the creator's privacy.

While the privacy principle was met by using materials which the subjects knew would be publicly available, historical creators especially may not have envisioned their words being searchable on the internet or used for this purpose. For interviews appearing in materials with small press runs or largely read by a specific group, creators may also not have anticipated their statement of self-identification as African American being quoted in a national database. In regard to respecting the preferences of creators, LCDGT is a controlled vocabulary and synonyms or historically equivalent terms for "African American" were coded as "African Americans." This may not have accurately reflected some creator's identity or even the term they used to describe themselves.

(3) We acknowledge that we bring our biases to the workplace; therefore, we strive to overcome personal, institutional, and societal prejudices in our work.

The authors were catalogers with specialized expertise and knowledge in the professional values and ethics in librarianship as outlined broadly by the ALA Code of Ethics. They acknowledged that bias exists at the personal, institutional and standards levels and regularly questioned this bias while performing their cataloging work from 
describing creators in authority work to assigning subject headings and classification numbers on resources. Together their expertise included work in materials that often raise ethical questions in description: authority work of persons in diverse languages; culture-level record description for databases; archival, special collections and digital collections materials which often contain outdated and insensitive language and images; and children's materials with diverse subject matters and languages. Significant duties and responsibilities in their job descriptions include:

- Manages cataloging guidelines, practices, priorities, and workflows in accordance with international and national standards, protocols, and best practices

- Performs original and complex copy cataloging for resources regardless of issuing agency, subject content, or format

- In consultation with the university archivist, appropriate librarians, and other external stakeholders, establishes processing and cataloging priorities and for determining appropriate levels of access and description for materials

- Organizes and/or provides training and guidance to ensure that members of the cataloging and metadata unit are current in their skills

- Monitors national and international trends in cataloging, metadata, resource discovery, and introduces new ideas for potential implementation

- Serves as a resource for faculty and staff in the unit, the library, and the university laboratory schools' libraries, particularly on matters related to cataloguing, classification, and metadata

- Fosters a culture of productivity and user-centered practices 
- Serves as the resource person for the unit's authority control activities; creates Library of Congress name authorities and proposes subject headings as appropriate

- Oversees vendor-provided catalog records, batch loads, and revises for discoverability standards as appropriate

- Directly supports library’s digital initiatives and collections by devising and implementing original descriptive metadata creation and strategies to support discoverability and access

Despite having responsibilities which include complex decision-making in providing access and description, the investigators strongly felt that for them to describe a creator as African American (even with a citation showing the creator self-identified with that group) would be problematic and ill-advised. The newness of the LCDGT meant there were not case studies to consult in scholarly literature, and the authors were hesitant as members of a predominantly white profession (librarians) to use terms created by a government institution (Library of Congress) to describe members of a marginalized community (African Americans) without more extensive subject expertise. To help reduce the impact of their personal biases and provide this expertise the catalogers hired a history graduate student, Trumaine Mitchell, with experience in African American Studies. Fortunately, he was extremely knowledgeable and shared not only his research expertise but his own experiences which helped the investigators navigate potential cataloging issues such as how a mixed-race author might identify.

In the area of institutional bias, the authors were faculty librarians engaging in research as part of their assigned job duties. The study and findings therefore fell under the umbrella of academic freedom at the university. Although there were no attempts to halt the research or quash its findings (library administration was in fact very 
supportive), the added protection of academic freedom did reassure the investigators that there would not be direct professional repercussions for their research. The university offers a Minor in African American Studies which likely contributes to the number of works by Black creators in the library's collection and by extension, its catalog.

The study was conducted at, and funded by, a university with predominately white faculty and students (although enrolment by Black students was increasing prior to the COVID-19 outbreak). Wikipedia itself has a white male bias and researchers did not attempt to determine which entries in the Wikipedia "List of African-American Writers" were added by members of specific demographic groups, what evidence was used to add them to the list, or what Wikipedia editors may have done to help overcome their own biases. ${ }^{71}$

(4) We recognise that interoperability and consistent application of standards help our users find and access materials. However, all standards are biased; we will approach them critically and advocate to make cataloguing more inclusive.

The crux of the project was to examine if the Library of Congress criteria for inclusion of the LCDGT African Americans would correspond to the entries on the Wikipedia "List of African-American Writers." This would give some indication of how well the criteria developed by Library of Congress for use of an LCDGT matched public perception for at least one demographic group. Had the project found that there was significant disagreement (it did not) between Library of Congress criteria and the Wikipedia list further criticism may have been possible. Further, the LCDGT African Americans was chosen with the knowledge that it was already a valid term.

There may have been an opportunity to promote greater inclusivity by using a term from a more inclusive or nuanced vocabulary than the expansive LCDGT offered 
with its many categories. One vocabulary that could have been examined is the Chicano thesaurus which was specifically created to improve subject access due to the absence of existing subject heading lists for literature related to a population's experience. ${ }^{72}$ The vocabulary was created by the then Chicano Studies Library at the University of California, Berkeley in the 1960s (now part of the Ethnic Studies Library) in direct response to the LCSH. The thesaurus is still used in the bibliographic Chicano Database produced by the Ethnic Studies Library. An example of greater inclusivity from the thesaurus could be the term Chicanas versus the LCSH term Mexican American Women. ${ }^{73}$ While the Chicano thesaurus would likely not have been well suited to describing works by African American creators for this project, the decision to use LCDGT without at least looking for a more inclusive vocabulary was an oversight on the part of the researchers.

Even when there is interoperability and standards are applied consistently and approached critically, discoverability can be limited by the search tools used. When this project was started the library used Voyager and EBSCO Discovery Service (EDS) and Creator/Contributor Characteristics (MARC 386) fields were not displayed in faceted search results. The library moved to Alma and Primo VE soon after, and this software can be configured to display the 386 field; however, this will also display results added from other projects that may not have followed the Library of Congress criteria, or have been applied on an ad hoc basis. Cooperative cataloging is a tremendous boon for institutions and patrons but can also lead to inconsistent applications of standards. Finally, standards themselves change over time and can result in inconsistencies or the need for large retrospective projects. 
(5) We support efforts to make standards and tools financially, intellectually, and technologically accessible to all cataloguers, and developed with evidence-based research and stakeholder input.

The project used a controlled vocabulary developed by Library of Congress and a Wikipedia list developed by a community of users, both of which are freely available to any user with a computer with an internet connection and web browser. An SQL search created by Nancy Boulware, Library Information Technology Services Lab Manager and Voyager Specialist, to examine local holdings by authorized form of name was made freely available on the institution's cataloging consortia website. ${ }^{74}$ The project was in the process of adding citations to Name Title Authority Records to make them publicly available when a moratorium on the 024 field was established. Other projects and COVID-19 disruptions have prevented this work being resumed despite the 024 moratorium being lifted.

Even though the LCDGT and Wikipedia list were freely available, they were in English and therefore largely inaccessible to non-English speakers. The citations were also generated in English and not translated. The results of the project were therefore of limited use to catalogers who did not speak English. Additionally, these two sources were freely available to view and use, but it is not free to contribute to the Library of Congress (LC) vocabularies as it is in Wikipedia. While the Library of Congress initially accepted proposals for the new LCDGT vocabulary until it went through further evaluation, the process did not accept open contributions from the public. Training and membership in the Name Authority Cooperative Program (NACO) and Subject Authority Cooperative Program (SACO) require the expenditure of staff time and other resources. Financial and intellectual barriers also existed in other tools the project utilized. The widely used cataloging database tool OCLC Connexion and the 
RDA standards toolkit come with fees not only to use, but costs in training. These obstacles potentially prevent access to shared standards by catalogers at smaller institutions with less staff time and funding to contribute.

The investigators based conclusions on evidence found from their research, chiefly the finding that of the 381 names on the Wikipedia list 271 had works in the catalog and the grant employee located evidence that 247 (91\%) of those self-identified as African American. Additional information based on other statistics (15 names out of 381 did not have Name Authority Records, for example) was also provided. This evidence was used to support the thesis that the names on the Wikipedia "List of African-American Writers" were generally in agreement with the Library of Congress criteria for inclusion in the African Americans demographic group.

(6) We take responsibility for our cataloguing decisions and advocate for transparency in our institutional practices and policies.

For assistance and feedback with their cataloging decisions in using the LCDGT vocabulary, the authors held conversations with the Library of Congress Specialists that developed the vocabulary. Paul Frank and Janis L. Young were especially gracious with their time and expertise. The authors also attended the Applying Library of Congress Faceted Vocabularies workshop which included a focus on LCDGT held at the 2017 Online Audiovisual Catalogers (OLAC) conference. $^{75}$

At the outset of the project, the authors intended to share their processes and findings with the community so that others might learn from their experiences and build on it. Cataloging \& Classification Quarterly published their peer-reviewed paper describing processes and findings. The authors included the pre-published version of the paper in Illinois State University's institutional repository (ISU ReD). They also included a file with the SQL query that locates bibliographic records that include the 
authorized form of a heading (i.e., the authority record's 1XX) in a bibliographic record's $1 \mathrm{XX}$ or 7XX field in Voyager.

The authors reported on the project at a Research Roundtable for discussion with library colleagues at their institution. They shared findings at two national conferences, the 2018 ALA Annual Conference and the Americas Regional Council ARC18 OCLC Regional Council Meeting. They also deposited national conference presentation materials in their institutional repository. ${ }^{76}$

(7) We collaborate widely to support the creation, distribution, maintenance, and enrichment of metadata in various environments and jurisdictions.

The authors collaborated with multiple colleagues in various areas throughout the project. Before the project began, they determined if there was a use for demographic terms in catalog records at their institution. They consulted with History subject librarian Professor Vanette Schwartz when looking fora graduate student to hire for the grant. Professor Schwartz referred them to Dr. Toure Reed in the History Department who recommended three students with subject expertise in African American Studies. All three were interviewed and found to be strong candidates. The project selected a graduate student from the History Department based on his extensive background in conducting original research and knowledge of African American Studies.

In the area of cataloging, the authors sought feedback and guidance from the Library of Congress specialists who developed LCDGT and attended a workshop at a national conference (OLAC) to better learn from cataloging colleagues on best practices to apply this new vocabulary. They also asked questions of the cataloging community at large, and Jay Shorten and Adam Schiff provided valuable feedback and advice. 
The authors also connected with a wider community of knowledge by using Wikipedia. Merrilee Proffitt of OCLC Research was very generous with her time and expertise, especially in discussing Wikipedia lists and categories. More generally, the project collaborated in an open knowledge system and engaged with Wikipedia editors to expand access to knowledge and demographic terms. They incorporated links to Library of Congress Name Authority Records into the authority template in Wikipedia and included data from Wikidata to Library of Congress name authority records in the 024 field (until the moratorium Library of Congress imposed). This created a full circle linking knowledge between the two systems.

While it was out of scope for the initial project, it would likely be valuable to conduct user studies and consult with students and faculty using the sources the authors added metadata to. This would broaden their collaboration beyond the cataloging community, and likely provide valuable insights into where and how to best direct future efforts.

(8) We insist on diversity, equity, and inclusion in the workplace. We promote education, training, equitable pay, and a fair work environment for everyone who catalogues so that they can continue to support search and discovery.

Grant funding allowed a budget of $\$ 12 /$ hour for a graduate student subject expert (\$8.25/hour was the minimum wage in Illinois at the time of project). This was also approximately the pay for a monthly graduate student stipend converted to hourly wages. As this was a grant funded position, the investigators were not able to offer health or retirement benefits, and university policy prohibited them from offering employment beyond 26 hours per week. They were able to let the grant employee set his own schedule and provided a cubicle in the Cataloging and Acquisitions area of the library with a desktop computer and other needed hardware and software. 
Milner Library and Illinois State University provide financial funding for travel to conferences for presentations to promote research, and professional development and learning. Support from Milner and ISU funded travel for the presentations and workshops at conferences which fostered opportunities to collaborate and learn with colleagues outside of the institution. Travel funding for the graduate student researcher to attend conferences was not requested as part of the grant, although committing a graduate student to attending a conference before they were hired may have been presumptuous. Library faculty's job descriptions include scholarly productivity as a requirement and permits faculty time to conduct this research.

This project took place on a campus where the majority of faculty, staff and students are white, albeit enrollment from diverse populations is increasing. The project's grant employee, who was a history graduate student, possessed an extensive background in original research and knowledge in African American Studies. The authors held expertise and received training at their institution in cataloging material for special and archival collections, digital collections, and children's materials. These resources often include sensitive topics and materials representing historically underrepresented groups.

(9) We advocate for the value of cataloguing work within our organizations and with external partners.

Recognizing cataloging work is a valuable contribution to the university, the library approved and supported the authors' University Research Grant application study proposal and funded the project. The authors shared findings with the faculty member in the History Department that recommended the graduate student employee.

The library's annual report featured an article about the project's work. The library's Director of Communications, Erin Link, promoted the published article on 
social media through institutional Facebook and Twitter accounts, and an author informed the cataloging community through listservs and personal social media. The authors shared the project with OCLC Research Coordinator Merrilee Proffitt, whose focus was the beneficial relationships between Wikipedia and libraries. This conversation resulted in a panel presentation at the ALA Annual Meeting with several other librarians who were working with Wikipedia and linked data in cataloging.

The investigators were fortunate that the library administration and colleagues recognize and value cataloging work, which made advocating for their work easier. While they did update and thank contacts in the History Department, they may have been able to increase their impact by notifying students and faculty more widely of the project and its results. The lack of immediate results due to OPAC limitations (described above) may have lessened outside interest, which also lead the investigators to speculate that managing user expectations can be a critical part of advocating for the value of cataloging.

(10) We work with our user communities to understand their needs in order to provide relevant and timely services.

The Creator/Contributor Characteristics (MARC 386) field and LCDGT were both new, and the authors consulted with subject librarians on how best to apply them to provide access to users and what might be helpful for the student community. It can be particularly difficult to work with demographic terms, but the authors would prefer it be done carefully and thoughtfully with a higher level of engagement than other communities may choose to provide. There are numerous considerations surrounding ethical and moral issues of author characteristics and to assign a term based on ethnicity, rightfully so, requires a very high standard of proof. 
As this was a grant funded project, the authors did not inquire beyond the subject and reference librarians on which further demographic groups might be relevant to user's needs. Considering the project in light of the Cataloguing Code of Ethics did raise the question, however, of how they might have proceeded if the intent was to provide broader demographic group information for their current collection and incoming items. In that case they may have wished to contact student groups directly or conduct user studies on demographic information in faceted search results (research which is sorely lacking). It also led the authors to consider that when they added this information to shared records (especially in OCLC), they were creating it for other user communities as well, who may not find it useful or might even find it harmful. They did base their decisions on information in published sources but providing a convenient list of demographic information on creators could aid in efforts to censor members of certain groups or even place people in physical or other danger.

\section{Discussion}

In evaluating this project against the Cataloguing Code of Ethics, some observations became apparent. It was initially tempting to view the code as a checklist of things the authors did well, and not undertake further consideration; however, the introspection became more valuable when they viewed the code as a guide to thinking about ways in which the project succeeded and could have been improved. This helped the authors become aware of opportunities for future research, potential retrospective projects, and where their ethical practice in everyday work can be improved. While the general nature of the code can be seen as lacking specificity, it also encourages deeper engagement with cataloging work. 
The Cataloguing Code of Ethics also encouraged the authors to consider their work in both a local, or personal, and broader context. This highlighted that some practices can be controlled by an individual in their own application, while other practices are set at the institution, consortia, or national level. This further encouraged them to think about how they can best steer their cataloging towards more ethical practice. For some tasks this can be accomplished locally by working with stakeholders at the department or institutional level, for other tasks it may require effort to alter the practice of national or global institutions, or a break with standards in favor of more ethical practice.

The analysis of the project with the Cataloguing Code of Ethics expanded the authors' perspective on cataloging ethics. By going through the statements of principles, they realized their understanding of cataloging ethics fell specifically along statements three and four: addressing personal prejudices in the work and biases in standards and practices and implementing social justice and inclusivity for information users. They mainly focused on these two areas and did not carefully consider the other principles in the code when planning the project. While they may have met the other statements, it was not through a deliberate effort but more due to learned traits and values from responsibilities as a cataloger, such as contributing to records and sharing with the community.

The authors recognized other ethical issues that also need to be addressed in their work, although that may not always be possible or easily controlled based on the library's priorities and budget constraints. The exercise brought to light that they do not necessarily apply the same cataloging ethics to all formats. In particular, scrutiny and subject analysis are not applied to bulk record loads for electronic resources and their 
outsourced shelf-ready cataloging and processing records. For these resources they sacrifice detailed description and precision of searching for the sake of bulk loading large numbers of records and immediate access. They also do not review these records to apply other subject access points to ameliorate biases, although they do invest their time in doing this for digital collections items.

The authors also developed more awareness that financial and intellectual barriers exist in the tools they use daily. They belong to an institution that is a member of NACO and SACO, regularly contribute names to the Library of Congress Name Authority File and have the ability and training to propose terms to LCSH. They have access to the widely used cataloging database OCLC Worldcat, the RDA standards toolkit, and ClassWeb; all tools that require fees and training. Cost obstacles prevent accessibility to shared standards for catalogers from smaller institutions with less staff and funding to contribute.

On reflection on statement ten, the catalogers acknowledged more user studies should be conducted to improve their work. Subject librarians informed them that searching creators by demographic group terms can be useful for the library's users based on past queries. However, they did not conduct a direct study with users to better understand their needs. The topic of the characteristics of creators requires further exploration and could benefit from user studies with underrepresented and diverse racial and cultural groups to address biases and incorporate inclusivity in description for the information seeking needs of those populations. The Cataloguing Code of Ethics can be seen as symptomatic of the shift in cataloging from local work based on extensive documentation (AACR2, for example) to a more subjective local practice in a sometimes contradictory global context. The general principles in the Cataloguing Code 
of Ethics provide guidance that can lead users to more ethical practice, but especially in a global context this may not lead to universal consensus. However, by using the principles outlined in the code catalogers can navigate this uncertainty and make the best decisions for their local users and community. This may often preclude easy answers and well-defined practices but promises a more informed profession able to navigate complex ethical issues.

\section{Conclusions and Recommendations}

The authors found reviewing their project through the Cataloguing Code of Ethics to be a valuable exercise. It allowed them to consider their previous and current practice in ways they had not and provided valuable insight into how some cataloging can be considered both ethical and questionable depending on how it is viewed. Overall, the experience was both affirming and helped the authors identify ways their practice could be improved. While some specific criteria seemed more relevant to their project than others, all the statements of principles had some degree of relevance.

While it is was developed by the cataloging community and primarily marketed towards catalogers, other communities may also benefit from using the Cataloguing Code of Ethics to evaluate their work. Wikidata editors in particular have frequent discussions on issues such as privacy, the rights of people to be described (or not described) as they wish, and the ethical implications of metadata work. This may become more directly relevant to catalogers if linked data sources such as Wikidata are incorporated into cataloging metadata rather than developing additional national standards through Library of Congress. For example, a PCC Wikidata Pilot project is underway. If it is proposed that adding demographic information from Wikidata to catalog records or local search results is preferable to continuing to develop LCDGT, 
having practiced applying these ethical principles will be valuable experience in that conversation. In addition, laudable projects such as Cite Black Women may benefit from including demographic information in metadata, but that should be considered carefully and holistically before proceeding. ${ }^{77}$

Catalogers may wish to emphasize certain principles from the Cataloguing Code of Ethics based on their individual institution's values. While it may be ideal that catalogers meet all principles in their work, it is not always possible or even in the catalogers' control due to administration directives, conflicting priorities, system barriers, and the lack of resources and staff. Moreover, they will find some areas more important than others in their local practice based on their users' needs. Coordinating the institution's strategic goals with the principles from the Cataloguing Code of Ethics could provide better guidance and build a consensus from catalogers to build a local ethics framework to implement specifically in their work. Use of community developed vocabularies and knowledge bases like Wikipedia and Wikidata can help to limit the impact of bias in cataloging and metadata work. Statements three and four in the Cataloguing Code of Ethics ask that catalogers address biases, which can be complicated for some. Often it requires modifying practices and services through the lens of diversity, equity, and inclusion. There has been a wider interest in recognizing and acknowledging the consequences of using outdated terms from LCSH and challenging and refuting the notion of neutrality in cataloging. ${ }^{78}$ With tools readily available such as the Cataloging Lab platform, a wider community can send proposals collectively to revise and add to LCSH for improving the vocabulary that is used in so many libraries. Remaining neutral is not an option in libraries and the vast global and community driven information landscape. 
Libraries and institutions in the $21^{\text {st }}$ century have embedded diversity, equity, and inclusion principles into their values and strategic goals. Catalogers have also identified a greater need to acknowledge that their work is not neutral and mitigate bias in description. Karen Smith-Yoshimura states:

We acknowledge that we have implicit or hidden biases in our descriptive metadata as well. We may identify "African-American" images in photo collections but not "white" or Caucasian; Library of Congress Subject Headings only mention race when the person is not white (e.g., "Men” and “African-American men.”) Should we categorize all people? How can such categorization be objective? ${ }^{79}$

While answers to these and other ethical questions in cataloging and metadata will likely be an ongoing discussion rather than clear cut criteria, evaluating practice against the Cataloguing Code of Ethics served as a valuable experience and helped prepare the authors for these discussions while showing how they can more ethically serve their users and community.

${ }^{1}$ Dorothy B. Porter, "Review of A Library on the Negro by Mentor A. Howe and Roscoe E. Lewis." The Journal of Negro Education 10, no. 2 (1941): 264-66, https://doi.org/10.2307/2292559

${ }^{2}$ Frances Lydia Yocom, A List of Subject Headings for Books by and about the Negro. (New York: H.W. Wilson, 1940). This scholarship was brought to our attention by Violet Fox (@violetbfox) - Fox, Violet. Reminder that \#critcat/radical cataloging history doesn't begin \& end with Berman. See also Frances Yocom who wrote about the lack of subject headings for materials about African-Americans in 1940. October 1, 2021, 2:09 am. 
https:/twitter.com/violetbfox/status/1443835511777472528?ref src=twsrc\%5Etfw

(accessed November 18, 2021).

${ }^{3}$ Annette L. Hoage. The Library of Congress Classification in the United States. A Survey of Opinions and Practices, with Attention to Problems of Structure and Application (D.L.S. dissertation, School of Library Service, Columbia University. 1961). The scholarship of Anette L. Hoage (later Annette Hoage Phinazee) was brought to the authors' attention by a tweet from Harvey Long (@harvlong) - Long, Harvey. "Her name was Annette Phinazee. By all accounts, she was the GOAT. Her 1961 Columbia University dissertation was a critical examination of the LoC and its cataloging practices." September 30, 2021, 1:04 pm. https://twitter.com/harvlong/status/1443637915519754243?ref_src=twsrc\%5Etfw (accessed November 18, 2021).

${ }^{4}$ Cataloging Ethics Steering Committee, "Cataloguing Code of Ethics," Final Version, https://docs.google.com/document/d/1IBz7nXQPfr3U1P6Xiar9cLAkzoNX_P9fq7eHvzfSlZ 0/edit (accessed May 11, 2021).

${ }^{5}$ Cataloging Ethics Steering Committee, "Case Studies," https://sites.google.com/view/cataloging-ethics/home/case-studies (accessed May 25, 2021).

${ }^{6}$ Eric Willey and Angela Yon, "Applying Library of Congress Demographic Group Characteristics for Creators," Cataloging \& Classification Quarterly, 57, no. 6 (2019): 349368, https://doi.org/10.1080/01639374.2019.1654054

${ }^{7}$ Wikipedia contributors, "List of African-American writers," Wikipedia, The Free Encyclopedia, https://en.wikipedia.org/w/index.php?title=List_of_African-

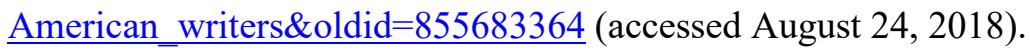

${ }^{8}$ Cataloging Ethics Steering Committee, "Cataloging Ethics Definition," Cataloging Ethics Steering Committee, https://sites.google.com/view/cataloging-ethics/home/ cataloging-ethics-definition (accessed September 25, 2021).

${ }^{9}$ Jennifer M. Martin, "Records, Responsibility, and Power: An Overview of Cataloging Ethics," Cataloging \& Classification Quarterly 59, nos. 2-3 (2021): 283, https://doi.org/10.1080/01639374.2020.1871458 
${ }^{10}$ Karen Snow and Beth Shoemaker, "Defining Cataloging Ethics: Practitioner Perspectives," Cataloging \& Classification Quarterly 58, no. 6 (2020): 544, https://doi.org/10.1080/01639374.2020.1795767

${ }^{11}$ Snow and Shoemaker, 535.

${ }^{12}$ Snow and Shoemaker, 543.

${ }^{13}$ Jennifer M. Martin, “Records, Responsibility, and Power: An Overview of Cataloging Ethics," Cataloging \& Classification Quarterly 59, nos. 2-3 (2021): 281-304, https://doi.org/10.1080/01639374.2020.1871458

${ }^{14}$ Martin, 287-288.

${ }^{15}$ Martin, 295.

${ }^{16}$ Martin, 295.

${ }^{17}$ Martin, 289.

${ }^{18}$ Martin, 290.

${ }^{19}$ Amelia N. Gibson, et al, "Libraries on the Frontlines: Neutrality and Social Justice.” Equality, diversity and inclusion: an international journal 36, no. 8 (2017): 751-766, https://doi.org/10.1108/EDI-11-2016-0100

${ }^{20}$ Kauffman, Rhonda Y., and Martina S. Anderson. "Diversity, Inclusion, and Social Justice in Library Technical Services.” Library Technical Services: Adapting to a Changing Environment, edited by Stacey Marien, Purdue University Press, West Lafayette, Indiana, 2020: 213-236.

${ }^{21}$ Kauffman and Anderson, 223.

${ }^{22}$ Kauffman and Anderson, 223-225.

${ }^{23}$ Violet Fox. "Creating Change in the Cataloging Lab: Peer to Peer Review." Library Journal. https://www.libraryjournal.com/?detailStory=creating-change-in-the-cataloging-lab-peer-topeer-review (accessed September 24, 2021).

${ }^{24}$ Introduction to Library of Congress Genre/Form Terms for Library and Archival Materials, 2021 edition. https://www.loc.gov/aba/publications/FreeLCGFT/freelcgft.html (accessed November 18, 2021) 
${ }^{25}$ Introduction of Library of Congress Demographic group Terms, 2020 edition. https://www.loc.gov/aba/publications/FreeLCDGT/2020\%20LCDGT\%20intro.pdf (accessed November 18, 2021).

${ }^{26}$ Krista Maywalt Aronson, Brenna D Callahan, and Anne Sibley O’Brien. “Messages Matter: Investigating the Thematic Content of Picture Books Portraying Underrepresented Racial and Cultural Groups," Sociological forum (Randolph, N.J.) 33, no. 1 (2018): 165-185.

${ }^{27}$ Aronson, et al., 183.

${ }^{28}$ Aronson, et al., 182.

${ }^{29}$ Rachel Ivy Clarke and Sayward Schoonmaker. "Metadata for Diversity: Identification and Implications of Potential Access Points for Diverse Library Resources," Journal of documentation 76, no. 1 (2020): 173-196.

${ }^{30}$ Clarke and Schoonmaker. 173.

${ }^{31}$ Clarke and Schoonmaker. 173.

${ }^{32}$ Clarke and Schoonmaker, 191.

${ }^{33}$ Hope A. Olson and Rose Schlegl, "Standardization, Objectivity, and User Focus: A MetaAnalysis of Subject Access Critiques," Cataloging \& Classification Quarterly 32, no. 2 (2001): 78, https://doi.org/10.1300/J104v32n02 06

${ }^{34}$ Brian M. Watson, "Bias and Inclusivity in Metadata.” (A Report on Julie Hardesty's Presentation to IndianaUniversity Bloomington), Archival Outlook, no. July/August (2019): $11,21$.

https://mydigitalpublication.com/publication/?i=601234\&p=1\&pp=1\&view=issueViewer.

${ }^{35}$ Rachel Ivy Clarke and Sayward Schoonmaker. "Metadata for Diversity: Identification and Implications of Potential Access Points for Diverse Library Resources," Journal of Documentation 76, no. 1 (2020): 173-196.

${ }^{36}$ Steven A. Knowlton, "Three Decades Since Prejudices and Antipathies: A Study of Changes in the Library of Congress Subject Headings," Cataloging \& Classification Quarterly 40, no. 2 (2005): 123-145, https://doi.org/10.1300/J104v40n02_08

${ }^{37}$ Knowlton, 127-28. 
${ }^{38}$ Knowlton, 128.

${ }^{39}$ Sara A. Howard and Steven A. Knowlton, "Browsing through Bias: The Library of Congress Classification and Subject Headings for African American Studies and LGBTQIA Studies," Library Trends 67, no. 1(Summer 2018): 74-88, https://doi.org/10.1353/lib.2018.0026

${ }^{40}$ Howard and Knowlton, 86.

${ }^{41}$ Howard and Knowlton, 77-78.

${ }^{42}$ Howard and Knowlton, 76, 86.

${ }^{43}$ Olson and Schlegl, 62.

${ }^{44}$ Patrick Keilty, "Tabulating Queer: Space, Perversion, and Belonging,” Knowledge

Organization 36, no. 4 (2009): 240-248, https://doi.org/10.5771/0943-7444-2009-4-240

${ }^{45}$ Keilty, 248.

${ }^{46}$ Keilty, 248.

${ }^{47}$ Keilty, 243.

${ }^{48}$ Molly Higgins, "Totally Invisible: Asian American Representation in the Dewey Decimal Classification, 1876-1996," Knowledge Organization 43, no. 8 (2016): 609-621, https://doi.org/10.5771/0943-7444-2016-8-609

${ }^{49}$ Higgins, 619.

${ }^{50}$ Violet Fox, "How do the editors decide which concepts get a Dewey number? An explainer." 025.431: The Dewey blog Everything you always wanted to know about the Dewey Decimal Classification ${ }^{\circledR}$ system but were afraid to ask ...” October 28, 2019. https://ddc.typepad.com/025431/2019/10/how-do-the-editors-decide-which-concepts-get-adewey-number-an-explainer.html (accessed November 18, 2021).

${ }^{51}$ Higgins, 619.

${ }^{52}$ Higgins, 620.

${ }^{53}$ Brian Dobreski and Barbara H. Kwaśnik, "Changing Depictions of Persons in Library Practice: Spirits, Pseudonyms, and Human Books," Knowledge Organization 44, no. 8 (2017): 656-667, http://dx.doi.org/10.5771/0943-7444-2017-8-656

${ }^{54}$ Dobreski and Kwaśnik, 665-666. 
${ }^{55}$ Dobreski and Kwaśnik, 666.

${ }^{56}$ Jinfang Niu, "Evolving Landscape in Name Authority Control," in Cataloging \& Classification Quarterly, 51, no. 4 (2013): 404-419, https://doi.org/10.1080/01639374.2012.756843

${ }^{57} \mathrm{Niu}, 418$.

${ }^{58} \mathrm{Niu}, 418$.

${ }^{59}$ Kelly J. Thompson, "More Than a Name: A Content Analysis of Name Authority Records for Authors Who Self-Identify as Trans," Library Resources \& Technical Services 60, no. 3:

140-155, https://doi.org/10.5860/1rts.60n3.140

${ }^{60}$ Thompson, 141.

${ }^{61}$ Thompson, 144

${ }^{62}$ Thompson, 152-153.

${ }^{63}$ Melanie Feinberg, "Hidden Bias to Responsible Bias: An Approach to Information Retrieval Systems Based on Haraway's Situated Knowledges," Information Research 12, no. 4 (2007) http://informationr.net/ir/12-4/colis/colis07.html

${ }^{64}$ Feinberg.

${ }^{65}$ Feinberg.

${ }^{66}$ Ruth Kitchin Tillman, "Barriers to Ethical Name Modeling in Current Linked Data Encoding Practices," in Ethical Questions in Name Authority Control, ed. Jane Sandberg (Sacramento, California: Library Juice Press, 2019), 243-259.

${ }^{67}$ Tillman, 247.

${ }^{68}$ Tillman, 252.

${ }^{69}$ Cataloging Ethics Steering Committee, "Cataloging Ethics Bibliography," https://docs.google.com/document/d/1bHtghhSL54PFlekIwnmHpF9O 2KR GMq5GWIBg NLKDg/edit (accessed June 28, 2021).

${ }^{70}$ Cataloging Ethics Steering Committee, "Cataloguing Code of Ethics, Part 2-Statements of Ethical Principles" Final Version, 
https://docs.google.com/document/d/1IBz7nXQPfr3U1P6Xiar9cLAkzoNX_P9fq7eHvzfSlZ

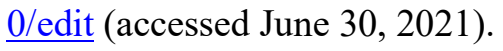

${ }^{71}$ Wikipedia contributors, “List of African-American writers," Wikipedia, The Free Encyclopedia, https://en.wikipedia.org/w/index.php?title=List_of_AfricanAmerican_writers\&oldid=855683364 (accessed June 30, 2021).

${ }^{72}$ Chicano Thesaurus, https://eslibrary.berkeley.edu/sites/default/files/thesauru.doc (accessed June 30, 2021).

${ }^{73}$ Ethnic Studies Library, UC Berkeley, "Chicano Studies Collection," https://eslibrary.berkeley.edu/chicano-studies-collection (accessed June 30, 2021).

${ }^{74}$ The consortia has since moved to a different OPAC, and the page with the search was taken down. The search can still be accessed at: ISU ReD: Research and eData, "Additional Files: NB SQL code.docx" https://ir.library.illinoisstate.edu/fpml/100/ or directly accessed at https://ir.library.illinoisstate.edu/cgi/viewcontent.cgi?filename $=0 \&$ article $=1105 \&$ context $=\mathrm{fp}$ ml\&type=additional (accessed June 30, 2021).

${ }^{75}$ Adam L. Schiff, “Applying Library of Congress Faceted Vocabularies,” OLAC 2017 Conference, October 28, 2017, slides 108-112, https://faculty.washington.edu/aschiff/OLAC2017-ApplyingLCFacetedVocab.pptx (accessed September 13, 2021).

${ }^{76}$ ISU ReD: Research and eData, " Wikipedia and Libraries: Improving Metadata Through Collaboration," http://ir.library.illinoisstate.edu/fpml/96 (accessed June 30, 2021); ISU ReD: Research and eData, " Wikipedia List of African American Writers and Library of Congress Demographic Group Terms (LCDGT)," http://ir.library.illinoisstate.edu/fpml/97 (accessed June 30, 2021).

${ }^{77}$ Cite Black Women, "Home," https://www.citeblackwomencollective.org/ (accessed June 30, 2021).

${ }^{78}$ Violet Fox, Cataloging Lab, "Problem LCSH," https://cataloginglab.org/problem-lcsh/ (accessed June 30, 2021). 
${ }^{79}$ OCLC Research, "Creating metadata for equity, diversity, and inclusion," Hanging Together:

The OCLC Research Blog, https://hangingtogether.org/?p=6833 (accessed June 30, 2021). 